\title{
Predicting recurrent mitral regurgitation after mitral valve repair for severe ischemic mitral regurgitation
}

\author{
Irving L. Kron, MD, ${ }^{\mathrm{a}}$ Judy Hung, MD, ${ }^{\mathrm{b}}$ Jessica R. Overbey, MS, ${ }^{\mathrm{c}}$ Denis Bouchard, MD, ${ }^{\mathrm{d}}$ \\ Annetine C. Gelijns, PhD, ${ }^{\mathrm{c}}$ Alan J. Moskowitz, MD, ${ }^{\mathrm{c}}$ Pierre Voisine, MD, ${ }^{\mathrm{e}}$ Patrick T. O'Gara, MD, ${ }^{\mathrm{f}}$ \\ Michael Argenziano, MD, ${ }^{\mathrm{g}}$ Robert E. Michler, MD, ${ }^{\mathrm{h}}$ Marc Gillinov, MD, ${ }^{\mathrm{i}}$ John D. Puskas, MD, ${ }^{\mathrm{j}}$ \\ James S. Gammie, MD, ${ }^{\mathrm{k}}$ Michael J. Mack, MD, ${ }^{1}$ Peter K. Smith, MD,${ }^{\mathrm{m}}$ Chittoor Sai-Sudhakar, MD, \\ Timothy J. Gardner, MD, ${ }^{\circ}$ Gorav Ailawadi, MD, ${ }^{a}$ Xin Zeng, MD, ${ }^{\mathrm{b}}$ Karen O'Sullivan, MPH, \\ Michael K. Parides, PhD, ${ }^{c}$ Roger Swayze, RN, BSN, ${ }^{\mathrm{h}}$ Vinod Thourani, MD, ${ }^{\mathrm{j}}$ Eric A. Rose, MD, \\ Louis P. Perrault, MD, ${ }^{\mathrm{d}}$ and Michael A. Acker, MD, ${ }^{\mathrm{p}}$ for the CTSN Investigators
}

\begin{abstract}
Objectives: The Cardiothoracic Surgical Trials Network recently reported no difference in the primary end point of left ventricular end-systolic volume index at 1 year postsurgery in patients randomized to repair $(n=126)$ or replacement $(\mathrm{n}=125)$ for severe ischemic mitral regurgitation. However, patients undergoing repair experienced significantly more recurrent mitral regurgitation than patients undergoing replacement ( $32.6 \%$ vs $2.3 \%$ ). We examined whether baseline echocardiographic and clinical characteristics could identify those who will develop moderate/severe recurrent mitral regurgitation or die.
\end{abstract}

Methods: Our analysis includes 116 patients who were randomized to and received mitral valve repair. Logistic regression was used to estimate a modelbased probability of recurrence or death from baseline factors. Receiver operating characteristic curves were constructed from these estimated probabilities to determine classification cut-points maximizing accuracy of prediction based on sensitivity and specificity.

Results: Of the 116 patients, 6 received a replacement before leaving the operating room; all other patients had mild or less mitral regurgitation on intraoperative echocardiogram after repair. During the 2-year follow-up period, 76 patients developed moderate/severe mitral regurgitation or died (53 mitral regurgitation recurrences, 13 mitral regurgitation recurrences and death, and 10 deaths). The mechanism for recurrent mitral regurgitation was largely mitral valve leaflet tethering. Our model (including age, body mass index, sex, race, effective regurgitant orifice area, basal aneurysm/dyskinesis, New York Heart Association class, history of coronary artery bypass grafting, percutaneous coronary intervention, or ventricular arrhythmias) yielded an area under the receiver operating characteristic curve of 0.82 .

Conclusions: The model demonstrated good discrimination in identifying patients who will survive 2 years without recurrent mitral regurgitation after mitral valve repair. Although our results require validation, they offer a clinically relevant risk score for selection of surgical candidates for this procedure. ( $\mathrm{J}$ Thorac Cardiovasc Surg 2015;149:752-61)

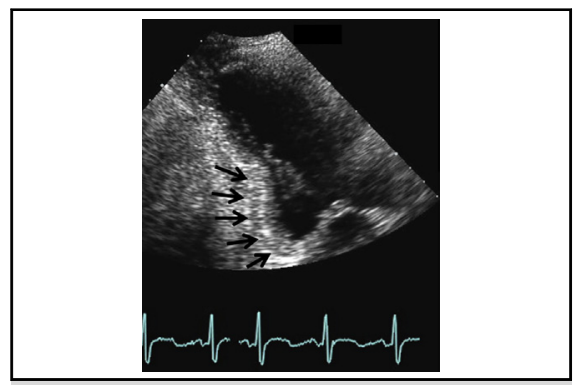

Basal aneurysm/dyskinesis is an important predictor of recurrent MR after ischemic MR repair.

\section{Central Message}

Using data from the CTSN severe ischemic MR trial, we developed a model to predict MR recurrence in MV repair patients. This exploratory model, based on baseline clinical and echocardiographic characteristics, showed good discrimination (area under $\mathrm{ROC}=0.82$ ) in identifying those patients who survived 2 years without recurrent ischemic MR.

\section{Author Perspective}

The severe ischemic MR trial showed equivalent clinical outcomes for patients undergoing mitral-valve replacement and repair. One distinction between the groups was that a third of the repair patients developed moderate/severe MR within a few months of the surgery. Among survivors, those with most improved ventricular dimensions were repair patients, who did not experience recurrence. We analyzed factors that led to recurrence and developed a 10-factor exploratory model that predicted this outcome. Our results offer a better understanding of when repair will be successful and of mechanisms of failure that may lead to more innovative repair techniques. 


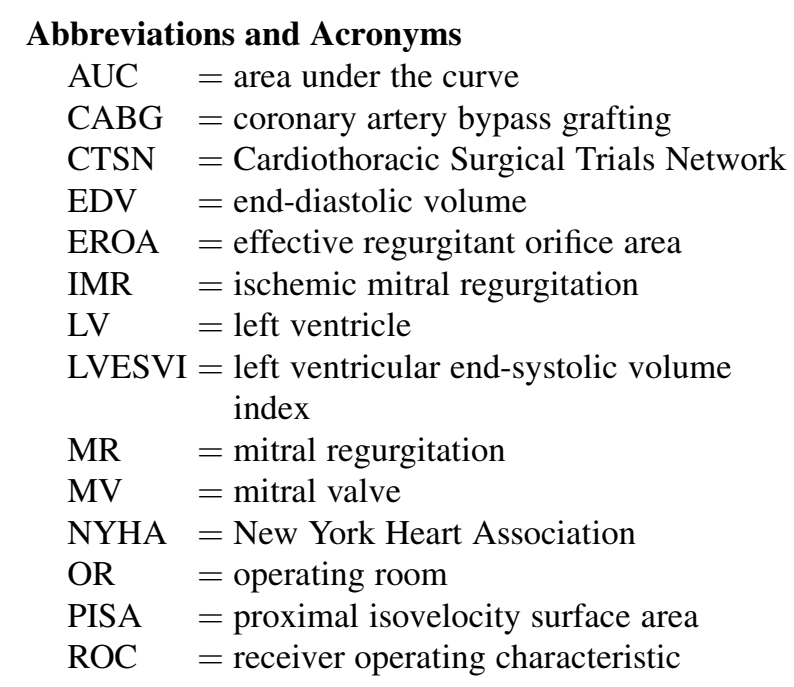

Supplemental material is available online.

Ischemic mitral regurgitation (IMR) is a common complication of coronary artery disease, which carries an adverse prognosis, increasing the risk of late death by a factor of 2. ${ }^{1}$ It occurs in approximately $25 \%$ of patients after myocardial infarction and is seen in up to $50 \%$ of patients with heart failure and cardiomyopathy.,3 Mitral regurgitation (MR) frequently occurs in patients with global left ventricle (LV) dysfunction and is a potent stimulus for adverse LV remodeling, which begets further MR. The mechanism of IMR relates to remodeling and distortion of the ischemic LV after infarction. ${ }^{4-7}$ Ischemic LV distortion, such as occurs with development of an inferior aneurysm, leads to myocardial thinning and displacement, which supports the papillary muscles,

\footnotetext{
From the Division of Thoracic and Cardiovascular Surgery, ${ }^{a}$ University of Virginia School of Medicine, Charlottesville, Va; Division of Cardiology, ${ }^{\mathrm{b}}$ Massachusetts General Hospital, Boston, Mass; International Center for Health Outcomes and Innovation Research (InCHOIR) in the Department of Population Health Science and Policy, ${ }^{\mathrm{c}}$ Icahn School of Medicine at Mount Sinai, New York, NY; Montréal Heart Institute, ${ }^{\mathrm{d}}$ University of Montréal, Montréal, Québec, Canada; Institut Universitaire de Cardiologie de Quebec, ${ }^{\mathrm{e}}$ Hopital Laval, Quebec, Canada; Cardiovascular Division, ${ }^{\mathrm{f}}$ Brigham and Women's Hospital, Boston, Mass; Division of Cardiothoracic Surgery, ${ }^{\mathrm{g}}$ Department of Surgery, College of Physicians and Surgeons, Columbia University, New York, NY; Department of Cardiothoracic Surgery, ${ }^{\text {h }}$ Montefiore Medical Center/Albert Einstein College of Medicine, New York, NY; Department of Thoracic and Cardiovascular Surgery, ${ }^{\mathrm{i}}$ Cleveland Clinic Foundation, Cleveland, Ohio; Department of Cardiac Surgery, ${ }^{j}$ Mount Sinai Beth Israel, Cardiothoracic Surgery, Icahn School of Medicine at Mount Sinai, New York, NY; Division of Cardiac Surgery, ${ }^{k}$ University of Maryland, Baltimore, Md; Cardiothoracic Surgery, Baylor Research Institute, Baylor Scott \& White Health, Plano, Tex; Division of Cardiovascular and Thoracic Surgery, ${ }^{\mathrm{m}}$ Duke Uni-
}

which in turn anchors the mitral leaflets. Thus, displacement of the papillary muscles tethers the leaflets, affecting leaflet closure, and results in MR. Fundamentally, the mechanism of ischemic MR relates to a mismatch in the normal ventricular mitral valve (MV) spatial geometry.

The preferred method for surgical correction for severe IMR, specifically the choice between repair and replacement, has long been debated. ${ }^{8-10}$ Previous studies have suggested that MV repair can be performed with lower perioperative mortality than replacement, but with high MR recurrence rates. ${ }^{8,11-13}$ Specifically, repairing the MV with a restrictive annuloplasty ring may not eliminate the mechanistic problem in ischemic MR, which is leaflet tethering from a distorted ischemic LV wall. The Cardiothoracic Surgical Trials Network (CTSN) recently published results of a randomized trial $(\mathrm{n}=251)$ comparing complete chordal-sparing MV replacement with MV repair with a complete downsized ring in patients with severe ischemic MR. In this trial, both surgical approaches reduced left ventricular end-systolic volume index (LVESVI) at 12 months, although there was no difference in 1-year LVESVI between the 2 treatment arms (the primary end point). Although 1-year mortality was similar in both groups, $32.6 \%$ of patients in the repair group developed moderate or severe MR at 1 year compared with only $2.3 \%$ in replacement group $(P<.001)$. Of note, at 1 year, patients in the repair group without recurrent MR demonstrated greater improvement in LVESVI (ie, lower) than those with moderate or severe MR recurrence $\left(47 \pm 23 \mathrm{~mL} / \mathrm{m}^{2}\right.$ vs $64 \pm 24$ $\left.\mathrm{mL} / \mathrm{m}^{2}, P<.001\right){ }^{14}$

Given these data, the question that emerges is whether one can identify a subgroup of patients who would most benefit from undergoing MV repair. Thus, the primary objective of this analysis is to determine whether we can discriminate between those patients who will experience moderate/severe MR recurrence after MV repair and those

versity, Durham, NC; Cardiac Surgery, ${ }^{\mathrm{n}}$ The Ohio State University Medical Center Columbus, Ohio; Center for Heart \& Vascular Health, ${ }^{\circ}$ Christiana Care Health System, Newark, Del; and Division of Cardiovascular Surgery, ${ }^{\mathrm{p}}$ Department of Surgery, University of Pennsylvania School of Medicine, Philadelphia, Pa.

A complete list of the CTSN Investigators can be found in Appendix E1.

Funded by a cooperative agreement of The National Heart, Lung, and Blood Institute, Bethesda, Md; the Canadian Institutes of Health Research, Ottawa, Ontario; and the National Institute of Neurological Diseases and Stroke, Bethesda, Md (Grant 7U01 HL088942). (ClinicalTrials.gov number NCT00807040).

Received for publication May 15, 2014; revisions received Oct 14, 2014; accepted for publication Oct 30, 2014; available ahead of print Dec 11, 2014.

Address for reprints: Annetine C. Gelijns, PhD, InCHOIR, Department of Population Health Science and Policy, Icahn School of Medicine at Mount Sinai, New York, NY 10029 (E-mail: Annetine.gelijns@mountsinai.edu). 0022-5223/\$36.00

Copyright (C) 2015 by The American Association for Thoracic Surgery http://dx.doi.org/10.1016/j.jtcvs.2014.10.120 
who will not, on the basis of preoperative clinical and echocardiographic data. In addition, this analysis gives a window into the evolution of recurrence of MR in this population over 2 years.

\section{MATERIALS AND METHODS Study Design}

In the parent trial, patients with chronic, severe IMR were randomly assigned (1:1 ratio) to MV repair or replacement. Randomization was stratified by center and blocked to ensure ongoing equivalence of group size. The trial randomized 251 patients between 2009 and 2012. Investigators were blinded to overall outcome data. This trial was conducted at 22 centers with a Coordinating Center, an independent event adjudication committee, and a data and safety monitoring board overseeing trial progress. Participating center institutional review boards approved the protocol, and all patients gave informed consent.

\section{Patients}

The target population was adults with severe IMR and coronary artery disease, eligible for MV surgical repair or replacement, with or without coronary artery bypass grafting (CABG). Severe IMR was assessed by resting transthoracic echocardiogram, using integrative criteria ${ }^{11}$ that were verified by an independent core laboratory. ${ }^{15}$ Severe MR was defined by an effective regurgitant orifice area (EROA) $0.4 \mathrm{~cm}^{2}$ or greater if the EROA was less than $0.4 \mathrm{~cm}^{2}$. The assessment of MR severity was guided by associated findings, including jet area/left atrial area ratio, vena contracta, density of the mitral systolic continuous-wave Doppler profile, pulmonary vein systolic flow pattern, and left-sided chamber dimensions. Exclusion criteria included any echocardiographic evidence of structural (chordal or leaflet) MV disease or ruptured papillary muscle. Complete eligibility criteria have been reported. ${ }^{10}$ Although 126 patients were randomized to MV repair, 5 patients were determined intraoperatively to be poor candidates for a repair and 5 patients withdrew from the trial over time. This analysis includes 116 patients undergoing MV repair.

The protocol mandated using an approved complete rigid or semi-rigid annuloplasty ring, which was downsized for the annulus diameter. The type of ring selected was left to the discretion of the surgeon. All patients were to receive guideline-directed medical management by their treating cardiologist, including aspirin, lipid-lowering agents, beta-blockers, renin-angiotensin-aldosterone antagonists, and cardiac resynchronization therapy.

\section{Echocardiographic Measures and End Points}

The end points are moderate or severe MR recurrence over 2 years after surgery and moderate/severe MR recurrence or death over 2 years. Recurrence was measured by transthoracic echocardiography at 30 days and 6 , 12 , and 24 months, and verified by the Echo Core laboratory. To be categorized as having no recurrent MR, patients with missing studies needed to have less than moderate MR on at least 2 echocardiograms.

In terms of echocardiographic measures, LV internal dimensions at end diastole and end systole were measured at mid-ventricular level in the parasternal long-axis view. LV end-diastolic volume (EDV) and LV end-systolic volume (ESV) were measured using Simpson's biplane method and LVEF calculated as $\left(\right.$ EDV-ESV) $\times 100 / E D V .{ }^{16}$ Echocardiographic criteria for inferior basal aneurysm were evidence of thinning and localized LV dilation or distortion. Dyskinesis was the presence of outward displacement of the inferoposterior LV wall during systole. ${ }^{17,18}$ Basal aneurysm and dyskinesis were combined in 1 variable because they represent the anatomic and functional derangements of ischemic LV remodeling in IMR. The degree of MV regurgitation was graded using integrative assessment as recommended by the American Society of Echocardiography. ${ }^{15}$ Parameters assessed included mitral jet area as a percentage of left atrial area, vena contracta width, and calculation of EROA from the proximal isovelocity surface area (PISA) method. Vena contracta width was measured from a magnified parasternal long-axis view with the central beam through the leaflet tips. Vena contracta width was defined as the narrowest width of the proximal jet measured at or in the immediate vicinity of the MR orifice at the leaflet tips. Regurgitant orifice area was calculated using the formula: regurgitant orifice area $=2 \pi \times$ RPISA2 $\times$ Valiasing $/$ Vmax, where RPISA is the maximal PISA radius $(\mathrm{cm})$, valiasing is aliasing velocity of the proximal flow convergence $(\mathrm{cm} / \mathrm{s})$, and Vmax is the maximal velocity of continuous wave Doppler MR signal $(\mathrm{cm} / \mathrm{s})$. Severity of MR was graded on the basis of the current American Society of Echocardiography recommendations as mild $\left(<0.2 \mathrm{~cm}^{2}\right)$, moderate $\left(0.2-0.39 \mathrm{~cm}^{2}\right)$, and severe $\left(\geq 0.40 \mathrm{~cm}^{2}\right)$. Integrative assessment included a final determination of MR into the following grades: $1=$ none or trace; $2=$ mild; $3=$ moderate; $4=$ severe.

Measures of MV tethering included MV tenting area $\left(\mathrm{cm}^{2}\right)$, tenting height, and anterior and posterior leaflet angles measured in midsystole (Figure 1). ${ }^{7,19,20}$ LV sphericity index, a measure of adverse LV remodeling was calculated as a ratio of EDV or ESV divided by volume of sphere $\left(4 / 3 \pi \mathrm{L}^{3}\right)$, where $\mathrm{L}$ is longitudinal length of $\mathrm{LV}$ cavity in an apical 4-chamber view at end diastole and end systole. ${ }^{20}$ The larger the sphericity index, the more spherical the LV becomes, reflecting adverse LV remodeling. LV sphericity index is used as a surrogate for increased MV tethering due to adverse LV remodeling. Peak

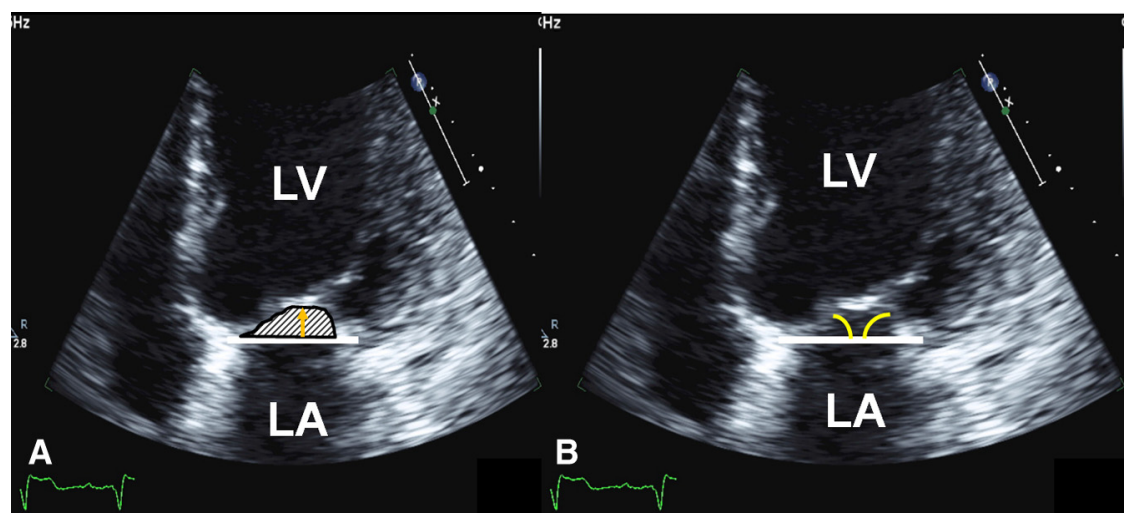

FIGURE 1. Echocardiographic measures of MV tethering. A, MV tenting area (hashmark area) and MV tenting height (gold arrow). B, Anterior and posterior leaflet angle measurements (yellow angle). $L A$, Left atrium; $L V$, left ventricle. 
TABLE 1. Comparison of baseline patient characteristics by outcome ("recurrence" or "recurrence and/or death")

\begin{tabular}{|c|c|c|c|c|c|c|}
\hline \multirow[b]{2}{*}{ Characteristic } & \multicolumn{3}{|c|}{ I } & \multicolumn{3}{|c|}{ II } \\
\hline & $\begin{array}{c}\text { No recurrence or } \\
\text { death }(N=40)\end{array}$ & $\begin{array}{l}\text { Recurrence and/or } \\
\text { death }(N=76)\end{array}$ & $P$ value & $\begin{array}{l}\text { No recurrence } \\
\quad(\mathbf{N}=\mathbf{4 4}) \dagger\end{array}$ & $\begin{array}{c}\text { Recurrence } \\
(\mathbf{N}=\mathbf{6 6}) \dagger\end{array}$ & $P$ value \\
\hline Age $(y)^{*}$ & $65.7 \pm 12.5$ & $70.6 \pm 8.6$ & .030 & $67.0 \pm 12.6$ & $69.6 \pm 8.7$ & .237 \\
\hline BMI $\left(\mathrm{kg} / \mathrm{m}^{2}\right)^{*}$ & $28.1 \pm 4.8$ & $26.7 \pm 4.3$ & .106 & $27.9 \pm 4.7$ & $27.0 \pm 4.4$ & .300 \\
\hline Male* & $28(70.0)$ & $42(55.3)$ & .123 & $30(68.2)$ & $37(56.1)$ & .202 \\
\hline White* & $36(90.0)$ & $59(77.6)$ & .100 & $40(90.9)$ & $50(75.8)$ & .044 \\
\hline $\mathrm{EDV}(\mathrm{mL})^{*}$ & $199.8 \pm 67.1$ & $193.6 \pm 63.2$ & .625 & $193.9 \pm 67.6$ & $198.7 \pm 62.0$ & .697 \\
\hline $\mathrm{EF}(\%)^{*}$ & $43.0 \pm 10.1$ & $41.8 \pm 11.9$ & .607 & $43.1 \pm 10.6$ & $41.5 \pm 11.3$ & .460 \\
\hline $\operatorname{EROA}\left(\mathrm{cm}^{2}\right)^{*}$ & $0.4 \pm 0.1$ & $0.4 \pm 0.2$ & .219 & $0.4 \pm 0.1$ & $0.4 \pm 0.2$ & .128 \\
\hline $\mathrm{ESV}(\mathrm{mL})^{*}$ & $116.9 \pm 51.5$ & $116.5 \pm 53.7$ & .974 & $113.2 \pm 51.4$ & $119.8 \pm 52.3$ & .515 \\
\hline LVEDD mid-ventricle $(\mathrm{cm})^{*}$ & $5.4 \pm 1.1$ & $5.5 \pm 0.9$ & .776 & $5.3 \pm 1.1$ & $5.6 \pm 0.9$ & .208 \\
\hline LVESD mid-ventricle $(\mathrm{cm})^{*}$ & $4.2 \pm 1.0$ & $4.4 \pm 1.0$ & .317 & $4.2 \pm 1.0$ & $4.5 \pm 1.0$ & .097 \\
\hline MR peak velocity $(\mathrm{cm} / \mathrm{s})^{*}$ & $494.2 \pm 53.1$ & $506.1 \pm 69.7$ & .351 & $497.9 \pm 54.2$ & $502.4 \pm 70.8$ & .721 \\
\hline Vena contracta $(\mathrm{cm})^{*}$ & $0.8 \pm 0.1$ & $0.8 \pm 0.1$ & .323 & $0.8 \pm 0.1$ & $0.8 \pm 0.1$ & .130 \\
\hline Angle (anterior-ap4) $\left(^{\circ}\right)^{*}$ & $23.6 \pm 6.1$ & $24.7 \pm 7.7$ & .435 & $23.4 \pm 5.9$ & $24.8 \pm 7.8$ & .315 \\
\hline Angle (posterior-ap4) $\left(^{\circ}\right)^{*}$ & $36.2 \pm 9.4$ & $37.2 \pm 10.2$ & .592 & $35.4 \pm 9.6$ & $38.0 \pm 10.2$ & .177 \\
\hline Sphericity index $(\mathrm{ED})^{*}$ & $0.6 \pm 0.1$ & $0.7 \pm 0.1$ & .465 & $0.6 \pm 0.1$ & $0.7 \pm 0.1$ & .168 \\
\hline Sphericity index $(\mathrm{ES})^{*}$ & $0.6 \pm 0.1$ & $0.6 \pm 0.1$ & .602 & $0.6 \pm 0.1$ & $0.6 \pm 0.1$ & .326 \\
\hline Tenting area $\left(\mathrm{cm}^{2}\right)^{*}$ & $2.1 \pm 0.6$ & $2.2 \pm 0.9$ & .601 & $2.1 \pm 0.7$ & $2.2 \pm 0.8$ & .288 \\
\hline Tenting height $(\mathrm{cm})^{*}$ & $1.0 \pm 0.3$ & $1.1 \pm 0.3$ & .465 & $1.0 \pm 0.3$ & $1.1 \pm 0.3$ & .209 \\
\hline Basal aneurysm/dyskinesis* & $8(20.0)$ & $44(57.9)$ & $<.001$ & $9(20.5)$ & $41(62.1)$ & $<.001$ \\
\hline NYHA class I + II & $10(25.0)$ & $40(52.6)$ & .004 & $13(29.5)$ & $34(51.5)$ & .022 \\
\hline NYHA class III + IV $*$ & $30(75.0)$ & $36(47.4)$ & & $31(70.5)$ & $32(48.5)$ & \\
\hline Planned revascularization* & $37(92.5)$ & $69(90.8)$ & 1.000 & $41(93.2)$ & $60(90.9)$ & .739 \\
\hline History of $\mathrm{AF}^{*}$ & $15(37.5)$ & $28(36.8)$ & .944 & $19(43.2)$ & $21(31.8)$ & .225 \\
\hline History of CABG* & $4(10.0)$ & 15 (19.7) & .178 & $4(9.1)$ & $13(19.7)$ & .132 \\
\hline $\begin{array}{l}\text { Chronic lung disease (moderate or } \\
\text { greater)* }\end{array}$ & $6(15.0)$ & $15(19.7)$ & .529 & $7(15.9)$ & $12(18.2)$ & .757 \\
\hline Diabetes & $15(37.5)$ & $30(39.5)$ & .836 & $15(34.1)$ & $27(40.9)$ & .471 \\
\hline History of heart failure* & $28(70.0)$ & $54(71.1)$ & .906 & $31(70.5)$ & $46(69.7)$ & .932 \\
\hline Hypertension* & $32(80.0)$ & $65(85.5)$ & .445 & $36(81.8)$ & $55(83.3)$ & .837 \\
\hline History of MI* & $33(82.5)$ & $60(78.9)$ & .648 & $36(81.8)$ & $51(77.3)$ & .566 \\
\hline History of PCI* & $13(32.5)$ & $34(44.7)$ & .202 & $15(34.1)$ & $30(45.5)$ & .235 \\
\hline History of renal insufficiency* & $12(30.0)$ & $17(22.4)$ & .367 & $13(29.5)$ & $13(19.7)$ & .234 \\
\hline Previous valve repair & $1(2.5)$ & $0(0.0)$ & .345 & $1(2.3)$ & $0(0.0)$ & .400 \\
\hline Previous valve replacement & $1(2.5)$ & $0(0.0)$ & .345 & $1(2.3)$ & $0(0.0)$ & .400 \\
\hline History of ventricular arrhythmia* & $8(20.0)$ & $6(7.9)$ & .074 & $10(22.7)$ & $3(4.5)$ & .004 \\
\hline
\end{tabular}

Data presented as N (\%) or mean \pm standard deviation. $A F$, Atrial fibrillation; $B M I$, body mass index; $C A B G$, coronary artery bypass grafting; $E D$, end diastole; $E D V$, enddiastolic volume; $E F$, ejection fraction; $E S$, end systole; $E S V$, end-systolic volume; $L V E D D$, left ventricular end-diastolic dimension; $L V E S D$, left ventricular end-systolic dimension; $M I$, myocardial infarction; $M R$, mitral regurgitation; NYHA, New York Heart Association; PCI, percutaneous coronary intervention; EROA, effective regurgitant orifice area. *Indicates the initial 30 variables that were candidates for the full model. $\dagger$ The 6 patient difference between the "recurrence or death" and recurrence alone outcome is the result of 6 patients dying before echocardiographic testing.

MR velocity, a measure of closing forces on the MV, was obtained by continuous-wave Doppler.

\section{Statistical Analysis}

Comparisons of preoperative characteristics between outcome groups were based on chi-square and $t$ tests. Our analytic strategy focuses on predicting recurrent MR, and recurrent MR or death, from a set of readily available preoperative patient characteristics. Logistic regression was used to reduce the set of patient characteristics into a probability of developing the outcome of interest, MR recurrence, or MR recurrence and/or death. These model-based probabilities were analyzed using receiver operating characteristic (ROC) curves. ROC curves are a graphic representation of the tradeoff between the false-negative and false-positive rates for every possible cutoff probability of recurrence (ie, recurrence or recurrence and or death). The area under the curve (AUC) summarizes information about outcome contained in the "predictor" set, with a value of 1 as maximum. To reduce the chance of over-fitting the models, we fit "reduced" models that included only variables whose univariate tests of associations with outcome, based on chi-square or $t$ tests, were less than 0.25 for the composite outcome of recurrent MR or death. This approach yielded a subset of 10 predictors from an original set of 30 (which are denoted with a star in Table 1). Because our data set is too small to be partitioned into a "training" set to fit the model, and a "validation" set to evaluate generalizability, we used a statistical method, cross-validation using a bootstrap approach, to assess generalizability. 


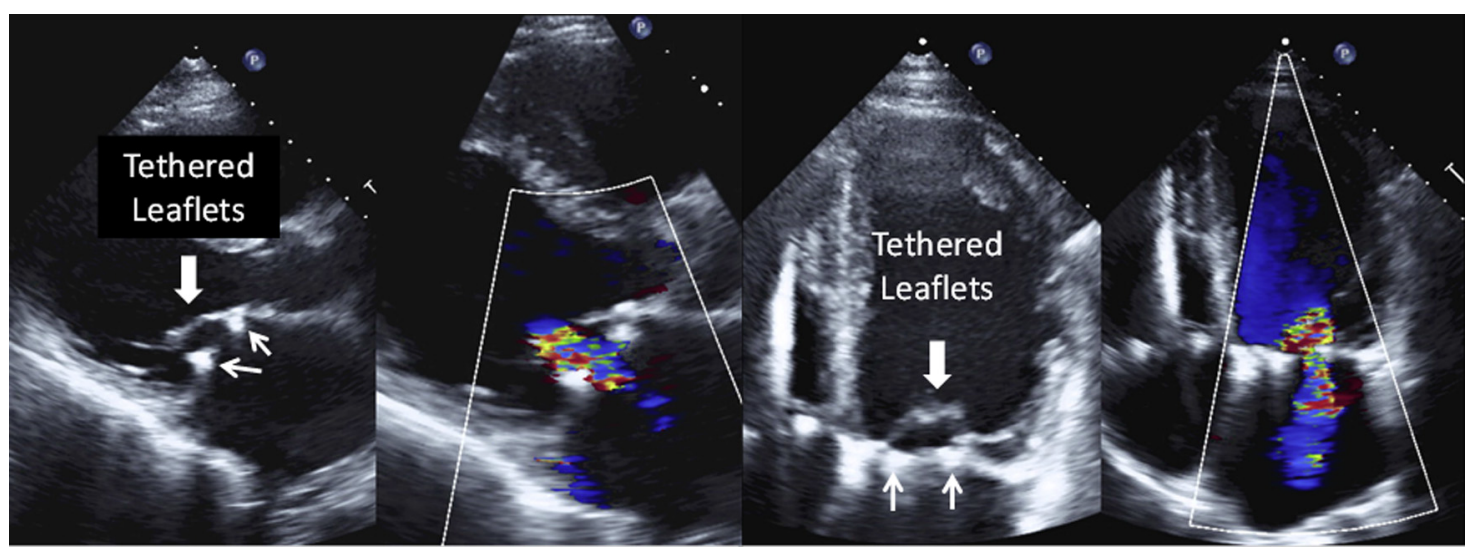

FIGURE 2. Tethering mechanism for recurrent MR after repair. Mitral leaflets remain tethered (large arrows) after MV ring annuloplasty (small arrows show ring) with moderate MR (blue and red color flow).

\section{RESULTS \\ Patients}

This study includes 116 patients who received MV repair. The echocardiography laboratory confirmed severe ischemic MR in $96 \%$ of patients, with $4 \%$ having moderate ischemic MR at enrollment. Table 1 depicts a comparison of baseline characteristics of patients stratified by outcome group. The first group compares patients who survived with less than moderate recurrent MR with patients who experienced moderate/severe MR recurrence or death. The patients who experienced an adverse outcome were older, had a higher frequency of basal aneurysm/dyskinesis, and had a lower frequency of New York Heart Association (NYHA) class III and IV. Likewise, in group II, which compares patients with less than moderate MR recurrence with patients with moderate or severe MR recurrence, those with recurrence had a higher frequency of basal aneurysm/dyskinesis, a history of ventricular arrhythmias, and a lower frequency of NYHA class III and IV.

Concomitant procedures were performed in $85 \%$ of patients: CABG (76\%), tricuspid valve repair $(11 \%)$, atrial ablation $(12 \%)$, and other procedures $(25 \%)$. Investigators used complete annuloplasty rings, with an average ring size of $28.3 \pm 1.9 \mathrm{~mm}$ for men and $27.3 \pm 1.7 \mathrm{~mm}$ for women.

\section{Outcomes Over Time}

Of the 116 patients, 6 received a replacement before leaving the operating room (OR) because repair did not sufficiently correct the MR; all other patients had mild or less MR on intraoperative transesophageal echocardiography after repair. By using transthoracic echocardiography follow-up data, the following rates of MR recurrences were observed for surviving patients (moderate, severe): $24.8 \%$ and $3.0 \%$ at 30 days, $25.5 \%$ and $4.3 \%$ at 6 months, $29.7 \%$ and $4.4 \%$ at 12 months, and $39.0 \%$ and $1.3 \%$ at 24 months, respectively. The mechanism for recurrent MR in these patients was MV leaflet tethering (Figure 2). In addition, ring dehiscence was observed in 4 patients ( 2 patients within 1 month, 1 patient at 9 months, and 1 patient at 13 months), who also received a valve replacement during the postoperative follow-up period. By taking into account these patients and patients who had uncorrected MR in the OR, the rates of moderate and severe MR were $23.8 \%$ and $9.9 \%$ at 30 days, $25.3 \%$ and $10.5 \%$ at 6 months, $29 \%$ and $10.8 \%$ at 12 months, and $38.0 \%$ and $10.1 \%$ at 24 months, respectively (Figure 3, A). The mortality rate was $14.7 \%$ at 1 year, and increased to $19.8 \%$ at 2 years. Thus, over time, a total of 76 patients experienced moderate/severe MR or death (53 MR recurrences, 13 MR recurrence and death, and 10 deaths). Figure 3, $B$, shows the increase in these events over the 2 years.

\section{Predicting Recurring Mitral Regurgitation}

None of the baseline echocardiographic measures of MV geometric tethering by themselves were associated with moderate/severe recurrent MR, but the presence of basal aneurysm/dyskinesis $(\mathrm{n}=52 / 116,45 \%)$ was strongly associated with this outcome (Figure 4). The probabilities of recurrent MR or death estimated from our multivariable model including age, body mass index, sex, race, EROA, basal aneurysm/dyskinesis, NYHA, prior $\mathrm{CABG}$, prior percutaneous coronary intervention, and history of ventricular arrhythmia yielded an AUC of 0.82 (Figure 5, A). The ROC curve for the corresponding model for recurrent MR alone as outcome had an AUC of 0.83 (Figure 5, B).

Both models provided good discrimination between outcomes, as shown by their diagnostic utility summarized by their sensitivity, specificity, positive predictive value, and negative predictive value (Table 2). Cross-validation indicates that the accuracy obtained by applying this discriminatory model to future patients was within $10 \%$ to $15 \%$ relative to that observed for the analysis set. All patients received a complete rigid or semi-rigid ring in the reduction annuloplasty. There was no association between ring size and MR recurrence. 


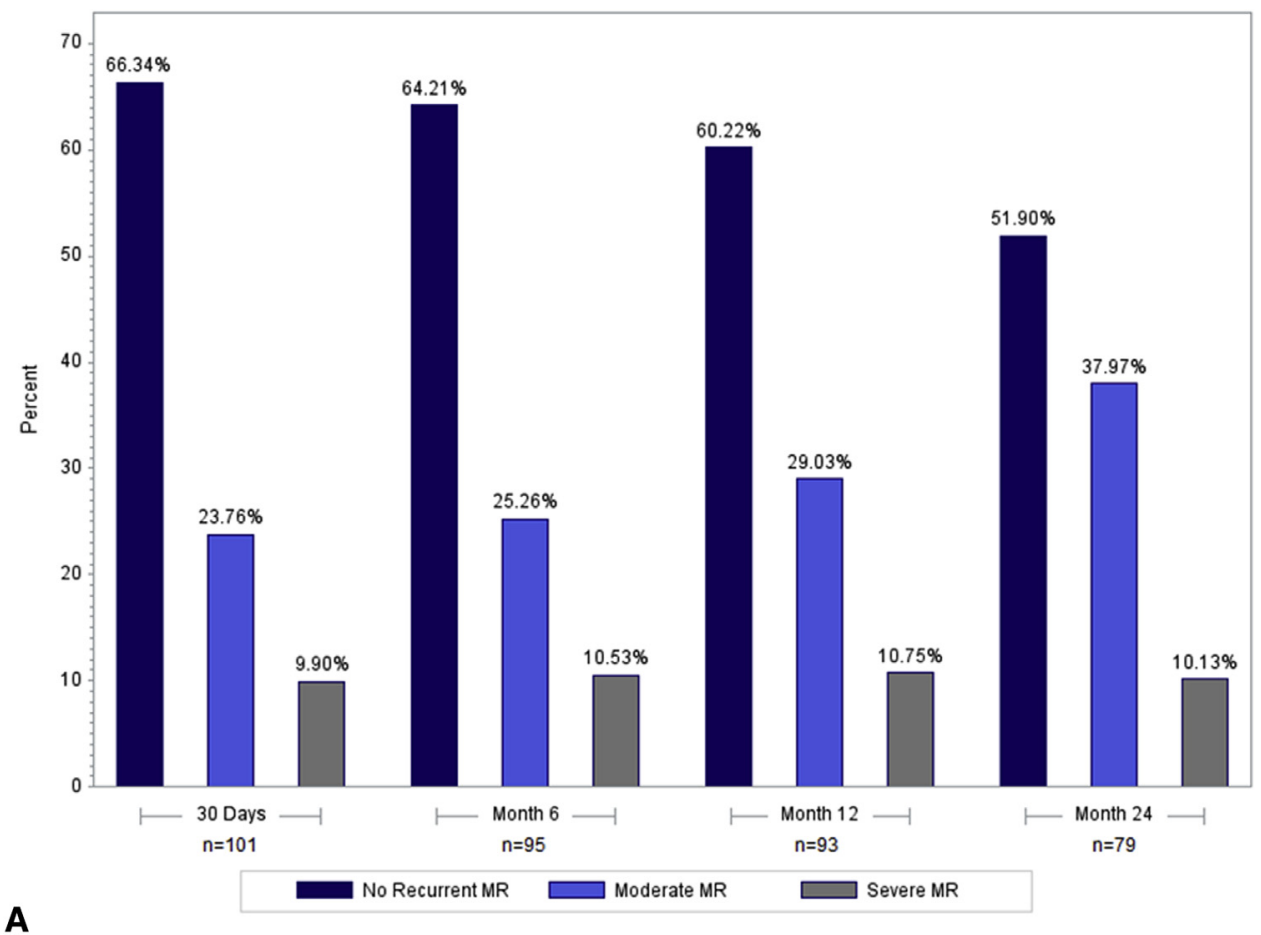

A

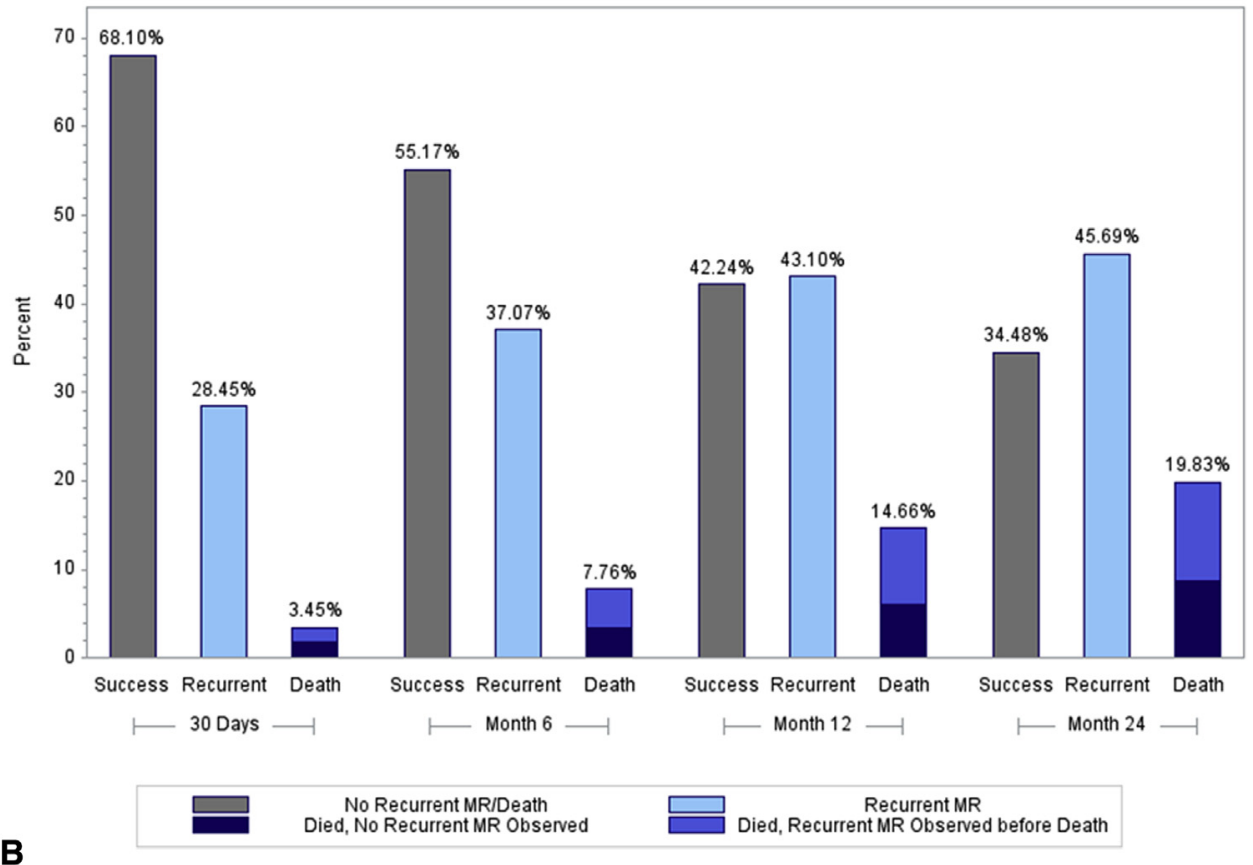

FIGURE 3. A, Moderate/severe MR at different time intervals. This bar graph depicts patients who were alive and had documented moderate/severe MR recurrence at that time point. Patients with missing echocardiograms are not included. B, Patients experiencing moderate/severe MR recurrence or death over 2 years. This histogram shows the cumulative proportion of patients who had moderate/severe MR recurrence or death at any point over the 2-year follow-up period. The denominator is 116 patients. $M R$, Mitral regurgitation.

\section{DISCUSSION}

We recently reported the results of a trial comparing MV repair with MV replacement for severe ischemic MR demonstrating that there was no significant difference in
LV reverse remodeling or survival at 12 months. ${ }^{14}$ However, we did show a $33 \%$ recurrence rate of moderate or severe MR at 12 months in the repair group. In this article, we sought to further define the time course of recurrent MR 


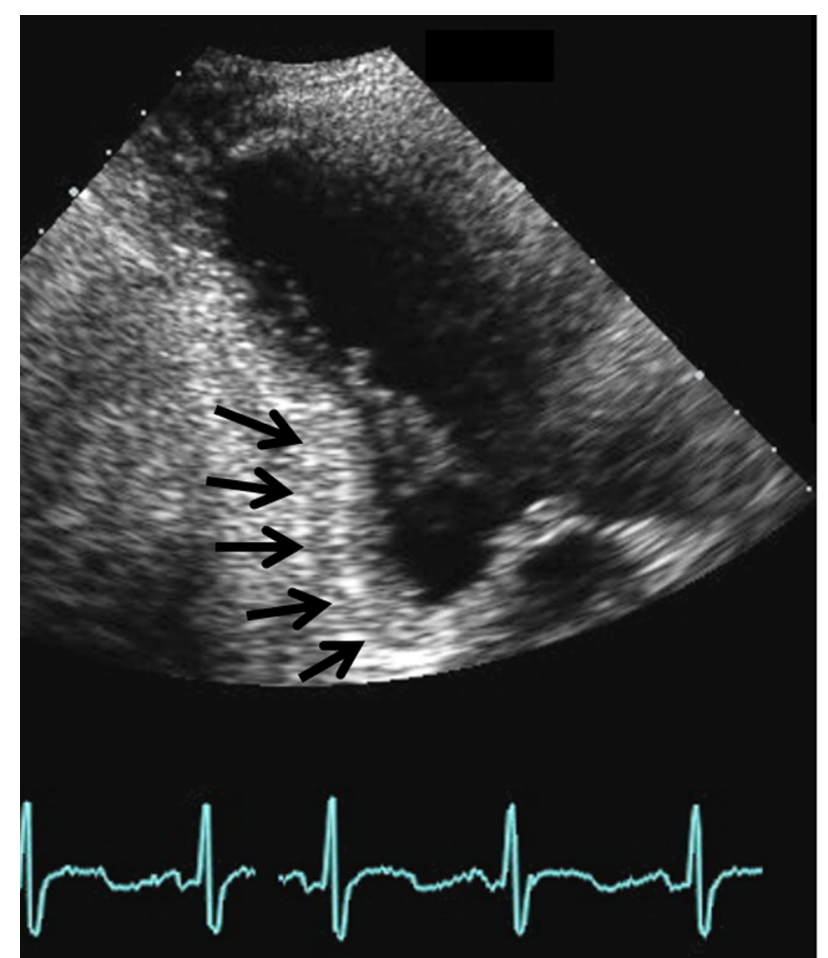

FIGURE 4. Basal aneurysm. Inferior basal aneurysm delineated by black arrows.

over 2 years and to determine whether we could identify a subset of patients at high risk for moderate and severe recurrence, on the basis of preoperative patient characteristics and echocardiographic parameters.

We analyzed 116 patients who received MR repair, 6 of whom underwent revision to MV replacement in the OR. The remaining 110 patients left the OR with mild or no MR by intraoperative transesophageal echocardiography. Recurrence of moderate or severe MR occurs early (30\% at 30 days). By 2 years, we find that $35 \%$ of patients are alive without having experienced moderate or severe MR recurrence, $46 \%$ of surviving patients have experienced 1 or more episodes of moderate or severe MR, and $20 \%$ of patients died (including 13/116 patients $[11 \%]$ with moderate/severe MR recurrence before death). The majority of patients had recurrent MR that was moderate in severity. Our study is one of the few that prospectively followed a cohort of patients with exclusively severe IMR at baseline who underwent MV repair with a restrictive annuloplasty ring with and without CABG, with serial echocardiograms over a 2 -year period. The literature clearly associates recurrent MR in patients who undergo repair with a restrictive annuloplasty ring with progressive or persistent LV remodeling and further leaflet tethering. ${ }^{3,21-25}$ Our findings confirm this observation (Figure 2). Hung and colleagues ${ }^{20}$ demonstrated that changes in MR paralleled increases in LV volumes and sphericity index at end systole and end diastole. Some $72 \%$ of patients had moderate or severe MR at late follow-up (47 months). The only independent predictor of late postoperative MR was LV sphericity index at end systole. ${ }^{20}$ Gelsomino and colleagues ${ }^{22}$ prospectively followed 251 patients who underwent combined CABG and undersized annuloplasty ring in those with chronic IMR. They found that the amount of recurrent moderate or severe MR was less than $10 \%$ at 1 year, but that the patients with moderate to severe MR increased to $33 \%$ at 3 years and to $72 \%$ at 5 years. ${ }^{22}$ Despite this high recurrence rate, there was an $83 \%$ survival and $78 \%$ of patients remained free of reoperation at 5 years.

In our study, it appears that, at least up to 2 years, there is not an inevitable progression of LV remodeling leading to recurrent MR nor does moderate MR inevitably progress to severe MR over that time period. It will be important to follow our patients for up to 5 years to determine if we see a similar increase in recurrence at 3 to 5 years as seen by Gelsomino and colleagues ${ }^{22}$ and to correlate the recurrence of MR with clinical outcomes over time. Of note, we also observed fluctuations in recurrent MR severity over time; for example, 9 of 25 patients with moderate to severe MR at 6 months improved to mild MR at 12 months. This suggests that recurrent MR, and the associated LV remodeling and leaflet tethering that occurs after MV repair with restrictive annuloplasty ring, is dynamic and can be modified with medical therapy in some patients.

Multiple groups have attempted to develop predictive models of recurrent MR based on preoperative parameters. ${ }^{22,26-35}$ The majority of these studies are retrospective single-center studies. There has been heterogeneity in variables that have been demonstrated to predict recurrent ischemic MR. Independent predictors of recurrent IMR fall into 2 categories: echocardiography parameters of leaflet tethering and degree of LV remodeling. Studies have demonstrated that echocardiography measures of increased tethering, such as anterior and posterior leaflet angle, tethering length, tenting area, and height, predict recurrent MR. Multiple groups point to the angle between the tip of the anterior leaflet and its relationship to the annular plane as the most important predictor of recurrence. An anterior leaflet angle greater than 25 to 39.5 degrees $^{21,28,29,32,36}$ was an independent predictor of recurrence and more important than any other measurement of tethering (eg, post-leaflet angle, coaptation depth, and tenting) or measurements of LV size or sphericity. Other groups point to LV size, LV function, or degree of MR as the key independent determinants of recurrent MR, ${ }^{22-24,27,34,35}$ whereas others point out the importance of both LV size and tethering as independent 

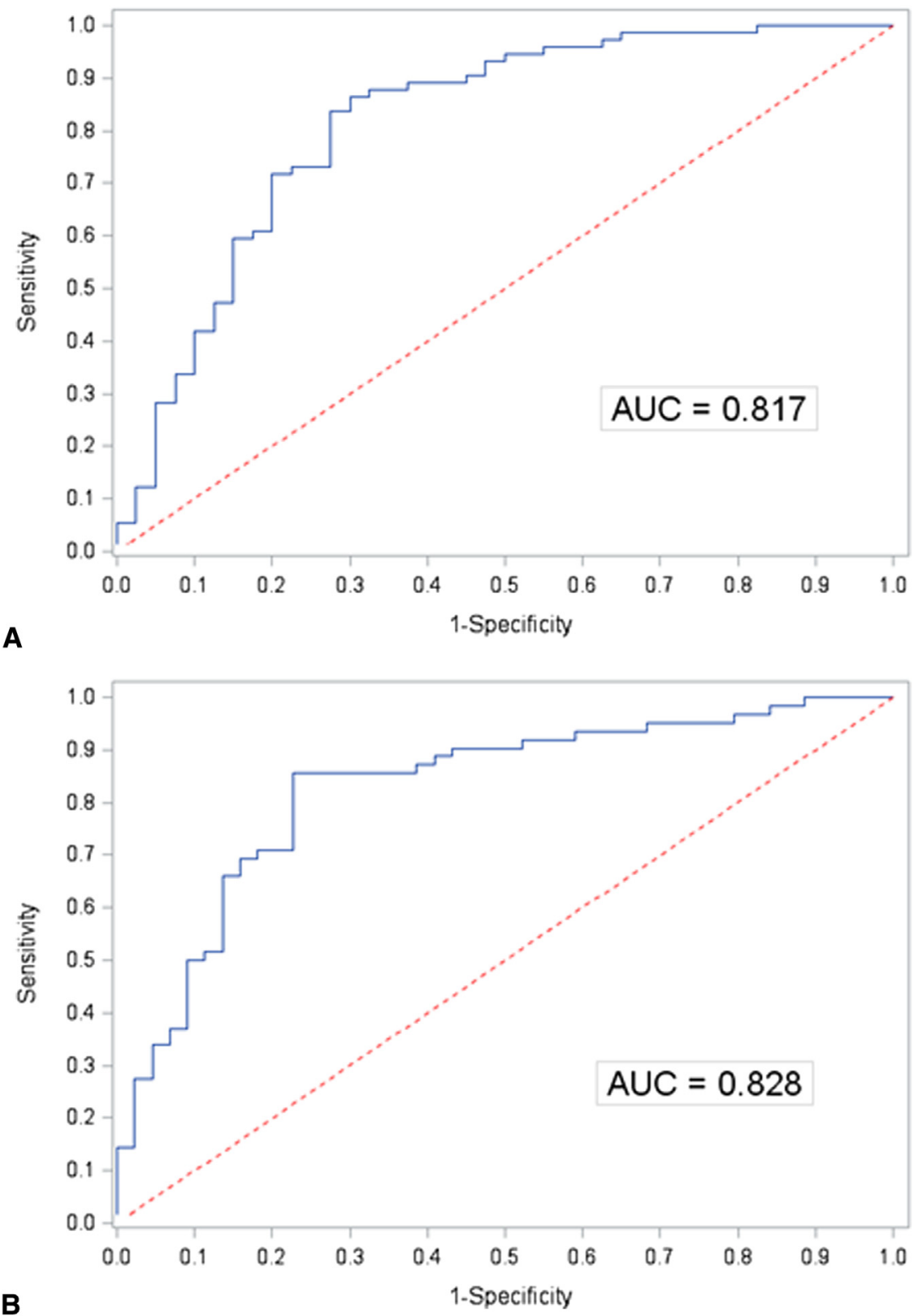

FIGURE 5. ROC curves of fitted models. A, ROC generated by reduced model of recurrence and/or death. B, ROC generated by fitted model of recurrence alone. $A U C$, Area under the curve.

predictors. ${ }^{30,31}$ Gelsomino and colleagues ${ }^{22}$ developed an ROC model of IMR recurrence after repair with a restrictive ring, and ESV $145 \mathrm{~mL}$ or greater, systolic sphericity index 0.7 or greater, myocardial performance index 0.9 or greater, and wall motion score index 1.5 or greater were predictors of recurrent MR.

In our study, univariate predictors of recurrence alone or recurrence and death at 24 months included the presence of a basal aneurysm/dyskinesis and NYHA. The relationship between NYHA and MR recurrence and death is likely confounded by the relationship between NYHA and basal aneurysm/dyskinesis ( $60 \%$ of basal aneurysms occurred in NYHA class I and II). Although tethering was present at the time of recurrence, no preoperative echocardiography parameters of leaflet tethering were predictive in our model. The variability in MV tethering and LV parameters that have been shown to predict IMR reflect the complexity and heterogeneity in factors that influence MV tethering and IMR. In our study, we combined both clinical and morphologic features of MV tethering by echocardiography to enhance the predictive algorithm. Of note, the presence of a basal inferior aneurysm/dyskinesis remained strongly associated 
TABLE 2. Observed utility for predicting recurrence and/or death and recurrence alone using the fitted model

\begin{tabular}{lcccc}
\hline \multicolumn{1}{c}{ Outcome } & Sensitivity & Specificity & PPV & NPV \\
\hline Recurrence and/or death & 0.86 & 0.70 & 0.84 & 0.74 \\
Recurrence & 0.89 & 0.80 & 0.86 & 0.83 \\
\hline
\end{tabular}

Cutoffs were selected such that the sum of sensitivity and specificity is maximized $N P V$, Negative predictive value; $P P V$, positive predictive value.

with recurrent IMR in our composite model. Basal inferior aneurysm/dyskinesis reflects a severe form of LV ischemic remodeling that incorporates the mechanistic abnormalities of papillary muscle displacement, leaflet tethering, and annular dilation, all of which influence ischemic IMR. An inferior basal aneurysm may better predict recurrent IMR than individual measures of MV tethering or LV remodeling because it integrates both leaflet tethering and LV remodeling measures. In our study, a large percentage $(45 \%)$ of patients had a basal aneurysm/dyskinesis.

With 10 variables (age, body mass index, sex, race, EROA, basal aneurysm/dyskinesis, NYHA, prior CABG and percutaneous coronary intervention, and history of ventricular arrhythmia), we were able to construct a model with reasonable classification accuracy, summarized by the AUC value of 0.82 . In addition, the corresponding values for sensitivity, specificity, positive predictive value, and negative predictive provide further evidence of the potential predictive value of our 10 candidate variables. These results demonstrate that a relatively small number of readily available preoperative patient characteristics have a strong potential to discriminate between patients who are likely to be good candidates for MV surgical repair and patients who are not.

After further validation, patients identified to be at high risk for postoperative MR recurrence should be considered for an MV replacement or a more complex repair operation that specifically addresses leaflet tethering. Several authors have reported encouraging early results with cutting secondary leaflet chords to directly relieve such leaflet tethering. ${ }^{37-40}$ Other procedures that directly relocate or sling the papillary muscles to decrease leaflet tethering also show promising results. ${ }^{41-43}$

\section{Study Limitations}

We do not have myocardial viability data on our patients or postoperative catheterizations to examine coronary artery bypass patency over time. As such, we cannot comment on the influence of hibernating myocardium on the presence or absence of recurrent MR over time. We cannot confirm the presence and severity of MR recurrence in patients who died between echocardiographic assessments. Finally, we stress that the models presented are preliminary in the sense that they represent a "discovery" or "proof-ofconcept" finding that must be subsequently validated.
Statistical approaches based on resampling methods were used to assess validity, but were limited by sample size and are not a substitute for reproducing good discrimination on a different sample of patients with IMR undergoing MV repair. Refinement and validation of our models are necessary for our ultimate goal of developing a "risk score" that clinicians and patients can use to inform treatment decisions.

\section{CONCLUSIONS}

Moderate and severe recurrent IMR after a restrictive annuloplasty ring, with or without $\mathrm{CABG}$, occurred early and affected a substantial proportion of patients by 2 years. Most of the MR was moderate, with little progression to severe MR, and the severity of MR was dynamic in that some patients with moderate MR subsequently developed mild MR. Basal aneurysms and dyskinesis, which occurred commonly in our patient population, were strongly associated with recurrent moderate or severe MR. We have developed a model that holds promise for predicting which patients will develop recurrent IMR so that they can be better treated with MV replacement or more complex repair techniques that directly address leaflet tethering.

\section{Conflict of Interest Statement}

Denis Bouchard reports lecture fees from Edwards and Sorin. Marc Gillinov reports consulting fees from On-X, Abbott, Edwards, Clearflow, and Atricure, and lecture fees from Medtronic. John D. Puskas reports lecture fees from Maquet. Gorav Ailawadi reports consulting fees from Abbott, Atricure, Medtronic, and Edwards. Vinod Thourani reports consulting fees from Edwards, Boston Scientific, and St. Jude. Louis P. Perrault reports consulting and lecture fees from ClearCath. Michael A. Acker reports consulting fees from Thoratec and Heartware. All other authors have nothing to disclose with regard to commercial support.

\section{References}

1. Lamas GA, Mitchell GF, Flaker GC, Smith SC Jr, Gersh BJ, Basta L, et al Clinical significance of mitral regurgitation after acute myocardial infarction. Survival and Ventricular Enlargement Investigators. Circulation. 1997;96: 827-33.

2. Koelling TM, Aaronson KD, Cody RJ, Bach DS, Armstrong WF. Prognostic significance of mitral regurgitation and tricuspid regurgitation in patients with left ventricular systolic dysfunction. Am Heart J. 2002;144:524-9.

3. Stevenson LW, Bellil D, Grover-McKay M, Brunken RC, Schwaiger M, Tillisch JH, et al. Effects of afterload reduction (diuretics and vasodilators) on left ventricular volume and mitral regurgitation in severe congestive heart failure secondary to ischemic or idiopathic dilated cardiomyopathy. Am J Cardiol. 1987; 60:654-8.

4. Godley RW, Wann LS, Rogers EW, Feigenbaum H, Weyman AE. Incomplete mitral leaflet closure in patients with papillary muscle dysfunction. Circulation. 1981;63:565-71.

5. Ogawa S, Hubbard FE, Mardelli TJ, Dreifus LS. Cross-sectional echocardiographic spectrum of papillary muscle dysfunction. Am Heart J. 1979;97:312-21. 
6. He S, Fontaine AA, Schwammenthal E, Yoganathan AP, Levine RA. Integrated mechanism for functional mitral regurgitation: leaflet restriction versus coapting force: in vitro studies. Circulation. 1997;96:1826-34.

7. Otsuji Y, Handschumacher MD, Schwammenthal E, Jiang L, Song JK, Guerrero JL, et al. Insights from three-dimensional echocardiography into the mechanism of functional mitral regurgitation: direct in vivo demonstration of altered leaflet tethering geometry. Circulation. 1997;96: 1999-2008.

8. Di Salvo TG, Acker MA, Dec GW, Byrne JG. Mitral valve surgery in advanced heart failure. J Am Coll Cardiol. 2010;55:271-82.

9. Lorusso R, Gelsomino S, Vizzardi E, D’Aloia A, De Cicco G, Lucà F, et al. Mitral valve repair or replacement for ischemic mitral regurgitation? The Italian Study on the Treatment of Ischemic Mitral Regurgitation (ISTIMIR). J Thorac Cardiovasc Surg. 2013;145:128-39; discussion 137-8.

10. Perrault LP, Moskowitz AJ, Kron IL, Acker MA, Miller MA, Horvath KA, et al. Optimal surgical management of severe ischemic mitral regurgitation: to repair or to replace? J Thorac Cardiovasc Surg. 2012;143:1396-403.

11. Gillinov AM, Wierup PN, Blackstone EH, Bishay ES, Cosgrove DM, White J, et al. Is repair preferable to replacement for ischemic mitral regurgitation? J Thorac Cardiovasc Surg. 2001;122:1125-41.

12. Reece TB, Tribble CG, Ellman PI, Maxey TS, Woodford RL, Dimeling GM, et al. Mitral repair is superior to replacement when associated with coronary artery disease. Ann Surg. 2004;239:671-7.

13. McGee EC, Gillinov AM, Blackstone EH, Rajeswaran J, Cohen G, Najam F, et al. Recurrent mitral regurgitation after annuloplasty for functional ischemic mitral regurgitation. J Thorac Cardiovasc Surg. 2004;128:916-24.

14. Acker MA, Parides MK, Perrault LP, Moskowitz AJ, Gelijns AC, Voisine P, et al. Mitral-valve repair versus replacement for severe ischemic mitral regurgitation. N Engl J Med. 2014;370:23-32.

15. Zoghbi WA, Enriquez-Sarano M, Foster E, Grayburn PA, Kraft CD, Levine RA, et al. Recommendations for evaluation of the severity of native valvular regurgitation with two-dimensional and Doppler echocardiography. J Am Soc Echocardiogr. 2003; 16:777-802.

16. Lang RM, Bierig M, Devereux RB, Flachskampf FA, Foster E, Pellikka PA, et al. Recommendations for chamber quantification: a report from the American Society of Echocardiography's Guidelines and Standards Committee and the Chamber Quantification Writing Group, developed in conjunction with the European Association of Echocardiography, a branch of the European Society of Cardiology. J Am Soc Echocardiogr. 2005;18:1440-63.

17. Weyman AE, Peskoe SM, Williams ES, Dillon JC, Feigenbaum H. Detection of left ventricular aneurysms by cross-sectional echocardiography. Circulation. 1976;54:936-44.

18. Armstrong WF, Thomas R. Evaluation of systolic function of the left ventricle. In: Armstrong WF, Thomas R, eds. Feigenbaum's Echocardiography. 7th ed. Hagerstown, MD: Lippincott Williams \& Wilkins; 2009:134-7.

19. Magne J, Pibarot P, Dagenais F, Hachicha Z, Dumesnil JG, Senechal M. Preoperative posterior leaflet angle accurately predicts outcome after restrictive mitral valve annuloplasty for ischemic mitral regurgitation. Circulation. 2007;115: 782-91.

20. Hung J, Papakostas L, Tahta SA, Hardy BG, Bollen BA, Duran CM, et al. Mechanism of recurrent ischemic mitral regurgitation after annuloplasty: continued LV remodeling as a moving target. Circulation. 2004;110:II85-90.

21. Magne J, Pibarot P, Dumesnil JG, Sénéchal M. Continued global left ventricular remodeling is not the sole mechanism responsible for the late recurrence of ischemic mitral regurgitation after restrictive annuloplasty. J Am Soc Echocardiogr. 2009;22:1256-64.

22. Gelsomino S, Lorusso R, De Cicco G, Capecchi I, Rostagno C, Caciolli S, et al. Five-year echocardiographic results of combined undersized mitral ring annuloplasty and coronary artery bypass grafting for chronic ischaemic mitral regurgitation. Eur Heart J. 2008;29:231-40.

23. Shiota M, Gillinov AM, Takasaki K, Fukuda S, Shiota T. Recurrent mitral regurgitation late after annuloplasty for ischemic mitral regurgitation. Echocardiography. 2011;28:161-6.

24. Crabtree TD, Bailey MS, Moon MR, Munfakh N, Pasque MK, Lawton JS, et al. Recurrent mitral regurgitation and risk factors for early and late mortality after mitral valve repair for functional ischemic mitral regurgitation. Ann Thorac Surg. 2008;85:1537-43.
25. Kuwahara E, Otsuji Y, Iguro Y, Ueno T, Zhu F, Mizukami N, et al. Mechanism of recurrent/persistent ischemic/functional mitral regurgitation in the chronic phase after surgical annuloplasty: importance of augmented posterior leaflet tethering Circulation. 2006;111:I529-34.

26. Braun J, van de Veire NR, Klautz RJ, Versteegh M, Holman ER, Westenberg JJ, et al. Restrictive mitral annuloplasty cures ischemic mitral regurgitation and heart failure. Ann Thorac Surg. 2008;85:430-7.

27. Ueno T, Sakata R, Iguro Y, Yamamoto H, Ueno M, Uemo T, et al. Preoperative advanced left ventricular remodeling predisposes to recurrence of ischemic mitral regurgitation with less reverse remodeling. J Heart Valve Dis. 2008;17: 36-41.

28. Lee AP, Acker M, Kubo SH, Bolling SF, Park SW, Bruce CJ, et al. Mechanisms of recurrent functional mitral regurgitation after mitral valve repair in non-ischemic dilated cardiomyopathy: importance of distal anterior leaflet tethering. Circulation. 2009;119:2606-14.

29. Gelsomino S, Garasse LV, Lucà F, Lorusso R, Cheriex E, Rao CM, et al Impact of preoperative anterior leaflet tethering on the recurrence of ischemic mitral regurgitation and the lack of left ventricular reverse remodeling after restrictive annuloplasty. J Am Soc Echocardiogr. 2011;24 1365-75.

30. Di Giammarco G, Liberi R, Giancane M, Canosa C, Gallina S, Di Francesco A et al. Recurrence of functional mitral regurgitation in patients with dilated cardiomyopathy undergoing mitral valve repair: how to predict it. Interact Cardiovasc Thorac Surg. 2007;6:340-4.

31. Ciarka A, Braun J, Delgado V, Versteegh M, Boersma E, Klaurtz R, et al. Predictors of mitral regurgitation recurrence in patients with heart failure undergoing mitral valve annuloplasty. Am J Cardiol. 2010;106:395-401.

32. Troubil M, Marcian P, Gwozdziewicz M, Santavy P, Langova K, Nemec P, et al Predictors of failure following restrictive annuloplasty for chronic ischemic mitral regurgitation. J Card Surg. 2012;27:6-12.

33. Onarati F, Rubino A, Marturano D, Pasceri E, Santarpino G, Zinzi S, et al Midterm clinical and echocardiographic results and predictors of mitral regurgitation on recurrence following restrictive annuloplasty for ischemic cardiomyopathy. J Thorac Cardiovasc Surg. 2009;138:654-62.

34. De Bonis M, Lapenna E, Verzini A, La Canna G, Grimaldi A, Torracca L, et al. Recurrence of mitral regurgitation parallels the absence of left ventricular reverse remodeling after mitral valve repair in advanced dilated cardiomyopathy. Ann Thorac Surg. 2008;85:932-9.

35. Lee LS, Kwon MH, Cevasco M, Schmitto JD, Mokashi SA, McGurk S, et al Postoperative recurrence of mitral regurgitation after annuloplasty for functional mitral regurgitation. Ann Thorac Surg. 2012;94:1211-7.

36. Haan CK, Cabral CI, Conetta DA, Coombs LP, Edwards FH. Selecting patients with mitral regurgitation and left ventricular dysfunction for isolated mitral valve surgery. Ann Thorac Surg. 2004;78:820-5.

37. Szymanski C, Bel A, Cohen I, Touchot V, Handschumacher MD, Desnos M, et al. Comprehensive annular and subvalvular repair of chronic ischemic mitral regurgitation improves long-term results with the least ventricular remodeling. Circulation. 2012;126:2720-7.

38. Borger MA, Murphy PM, Alam A, Fazel S, Maganti M, Armstrong S, et al. Initial results of the chordal-cutting operation for ischemic mitral regurgitation. $J$ Thorac Cardiovasc Surg. 2007;133:1483-92.

39. Magne J, Senechal M, Dumesnil JG, Pibarot P. Ischemic mitral regurgitation: a complex multifaceted disease. Cardiology. 2009:112:244-59.

40. Bouma W, van der Horst ICC, Wijdh-den-Hamer IJ, Erasmus ME, Zijlstra F, Mariani MA, et al. Chronic ischemic mitral regurgitation. Current treatment results and new mechanism-based surgical approaches. Eur J Cardiothorac Surg. 2010;37:170-85.

41. Fattouch K, Castrovinci S, Murana G, Dioguardi P, Guccione F, Nasso G et al. Papillary muscle relocation and mitral annuloplasty in ischemic mitral valve regurgitation: midterm results. J Thorac Cardiovasc Surg. 2014;148: $1947-50$.

42. Roshanali F, Cedadian A, Shoar S, Naderan M, Mandegar MH. Efficacy of papillary muscle approximation in preventing functional mitral regurgitation recurrence in high-risk patients with ischaemic cardiomyopathy and mitral regurgitation. Acta Cardiol. 2013;68:271-8.

43. Hvass U, Joudinaud T. The papillary muscle sling for ischemic mitral regurgitation. J Thorac Cardiovasc Surg. 2010;139:418-23. 


\section{APPENDIX E1}

The members of the Cardiothoracic Surgical Trials Network (CTSN) involved in this study are as follows: National Heart, Lung and Blood Institute: Marissa A. Miller, Wendy C. Taddei-Peters, Dennis Buxton, Ron Caulder, Nancy L. Geller, David Gordon, Neal O. Jeffries, Albert Lee; National Institute of Neurological Disorders and Stroke: Claudia S. Moy; Canadian Institutes of Health Research: Ilana Kogan Gombos, Jennifer Ralph; Network Chairs: Toronto General Hospital, Richard Weisel, (Chair); Christiana Care Health System, Timothy J. Gardner, (Chair-Emeritus); Brigham and Women's Hospital, Patrick T. O'Gara, (Co-Chair); Mount Sinai Health System, Eric A. Rose, (Vice Chair); Data Coordinating Center: International Center for Health Outcomes and Innovation Research at Icahn School of Medicine at Mount Sinai: Annetine C. Gelijns, Michael K. Parides, Deborah D. Ascheim, Alan J. Moskowitz, Ellen Moquete, Helena Chang, Melissa Chase, Yingchun Chen, Lopa Gupta, Katherine Kirkwood, Edlira Kumbarce, Ron Levitan, Karen O’Sullivan, Jessica Overbey, Milerva Santos, Michael Weglinski, Alan Weinberg, Paula Williams, Carrie Wood, Xia Ye;

Clinical Site Investigators: Baylor Research Institute: Michael Mack (PI), Tracine Adame, Natalie Settele, Jenny Adams, William Ryan, Robert L. Smith, Paul Grayburn; Brigham and Women's Hospital: Frederick Y. Chen (PI), Anju Nohria, Lawrence Cohn, Prem Shekar, Sary Aranki, Gregory Couper, Michael Davidson, R. Morton Bolman III, Anne Burgess, Debra Conboy; Cleveland Clinic Foundation: Eugene H. Blackstone (PI), A. Marc Gillinov, Pamela Lackner, Leoma Berroteran, Diana Dolney, Suzanne Fleming, Roberta Palumbo, Christine Whitman, Kathy Sankovic, Denise Kosty Sweeney; NHLBI Clinical Research Scholars: Gregory Pattakos, Pamela A. Clarke; Columbia University: Michael Argenziano (PI), Mathew Williams, Lyn Goldsmith, Craig R. Smith, Yoshifumi Naka, Allan Stewart, Allan Schwartz; Daniel Bell, Danielle Van Patten; Duke University: Peter K. Smith (PI), John H. Alexander, Carmelo A. Milano, Donald D. Glower, Joseph P. Mathew, J. Kevin Harrison, Stacey Welsh; NHLBI Clinical Research Scholars: Mark F. Berry, Cyrus J. Parsa, Betty C. Tong, Judson B. Williams; East Carolina Heart Institute: T. Bruce Ferguson (PI), Alan P. Kypson, Evelio Rodriguez, Malissa Harris, Brenda Akers, Allison O'Neal; Emory University: John D. Puskas (PI), Vinod H. Thourani, Robert Guyton, Jefferson Baer, Kim Baio, Alexis A. Neill; Hôpital Laval: Pierre Voisine (PI), Mario Senechal, François Dagenais,
Kim O'Connor, Gladys Dussault, Tatiana Ballivian, Suzanne Keilani; Inova Heart \& Vascular Institute: Alan M. Speir (PI), Patrick Magee, Niv Ad, Sally Keyte, Minh Dang; Jewish Hospital: Mark Slaughter (PI), Marsha Headlee, Heather Moody, Naresh Solankhi, Emma Birks; Mission Hospital: Mark A. Groh (PI), Leslie E. Shell, Stephanie A. Shepard, Benjamin H. Trichon, Tracy Nanney, Lynne C. Hampton; Montefiore-Einstein Heart Center, New York, NY: Robert E. Michler (PI), David A. D'Alessandro, Joseph J. DeRose, Jr, Daniel J. Goldstein, Ricardo Bello, William Jakobleff, Mario Garcia, Cynthia Taub, Daniel Spevak, Roger Swayze; Montreal Heart Institute: Louis P. Perrault (PI), Arsène-Joseph Basmadjian, Denis Bouchard, Michel Carrier, Raymond Cartier, Michel Pellerin, Jean François Tanguay, Ismael El-Hamamsy, André Denault, Jonathan Lacharité, Sophie Robichaud; NIH Heart Center at Suburban Hospital: Keith A. Horvath (PI), Philip C. Corcoran, Michael P. Siegenthaler, Mandy Murphy, Margaret Iraola, Ann Greenberg; Ohio State University Medical Center: Chittoor Sai-Sudhakar (PI), Ayseha Hasan, Asia McDavid, Bradley Kinn; Hôpital du Sacré-Coeur de Montréal: Pierre Pagé (PI), Carole Sirois; University of Maryland: James S. Gammie (PI), Cindi A. Young, Dana Beach; University of Pennsylvania: Michael A. Acker (PI), Y. Joseph Woo, Mary Lou Mayer; University of Southern California: Michael Bowdish (PI), Vaughn A. Starnes, David Shavalle, Ray Matthews, Shadi Javadifar, Linda Romar; University of Virginia: Irving L. Kron (PI), Gorav Ailawadi, Karen Johnston, John M. Dent, John Kern, Jessica Keim, Sandra Burks, Kim Gahring; Protocol Review Committee: David A. Bull (Chair); Patrice Desvigne-Nickens, Executive Secretary; Dennis O. Dixon, Mark Haigney, Richard Holubkov, Alice Jacobs, Frank Miller, John M. Murkin, John Spertus, Andrew S. Wechsler; Data and Safety Monitoring Board: Frank Sellke (Chair); Cheryl L. McDonald, Executive Secretary; Robert Byington, Neal Dickert, Dennis O. Dixon, John S. Ikonomidis, David O. Williams, Clyde W. Yancy; Medical Monitors: James C. Fang, Nadia Giannetti, Wayne Richenbacher; Overall Event Adjudication Committee: Vivek Rao (Chair); Karen L. Furie, Rachel Miller, Sean Pinney, William C. Roberts, Mary N. Walsh; Cardiopulmonary Exercise Core Lab, Henry Ford Hospital: Stephen J. Keteyian, Clinton A. Brawner, Heather Aldred; Echo Core Lab, Massachusetts General Hospital: Judy Hung, Xin Zeng; Neurocognitive Core Lab, Duke University Medical Center: Joseph P. Mathew, Jeffrey Browndyke, Yanne Toulgoat-Dubois. 